\title{
Internet Re
}

Others' fortune in online vs. offline settings: how envy affects people's intention to share information

\begin{tabular}{|r|l|}
\hline Journal: & Internet Research \\
\hline Manuscript ID & INTR-10-2019-0412.R4 \\
\hline Manuscript Type: & Research Paper \\
\hline Keywords: & $\begin{array}{l}\text { Word of mouth, Envy, Social networks, Consumer Behaviour, Digital, } \\
\text { Marketing }\end{array}$ \\
\hline \multicolumn{2}{|l}{} \\
\hline
\end{tabular}

\section{SCHOLARONE ${ }^{\text {"n }}$ \\ Manuscripts}




\section{Table 1}

Overview of the studies

\begin{tabular}{|c|c|c|}
\hline \multicolumn{3}{|c|}{$\begin{array}{l}\text { Predictions based on the framework } \\
\text { Online/offline setting: The intention to share information that may elicit envy is lower in } \\
\text { online than in offline settings. } \\
\text { Envy/no envy: In online settings, envy provoked by upward social comparisons negatively } \\
\text { affects people's intention to share information. }\end{array}$} \\
\hline Studies & Design & Main findings \\
\hline $\begin{array}{l}\text { Study } 1 \\
\text { Four scenarios } \\
\text { One-item self- } \\
\text { reported envy } \\
\text { measure }\end{array}$ & $\begin{array}{l}2(\text { envy/no envy) } \times 2 \\
\text { (online/offline) }\end{array}$ & $\begin{array}{l}\text { People's intention to share information that } \\
\text { generates envy is lower in online settings }\end{array}$ \\
\hline $\begin{array}{l}\text { Study } 2 \\
\text { Recall task } \\
\text { Multi-item self- } \\
\text { reported OSN- } \\
\text { situational envy } \\
\text { scale }\end{array}$ & $\begin{array}{l}2 \text { (envy/no envy) } \\
\text { Online setting }\end{array}$ & $\begin{array}{l}\text { In online settings, people's intention to } \\
\text { share information about others' } \\
\text { outperformance is lower under envious } \\
\text { feelings, which may occur when they visit } \\
\text { an OSN }\end{array}$ \\
\hline
\end{tabular}


Figure 1

People's intention to share information

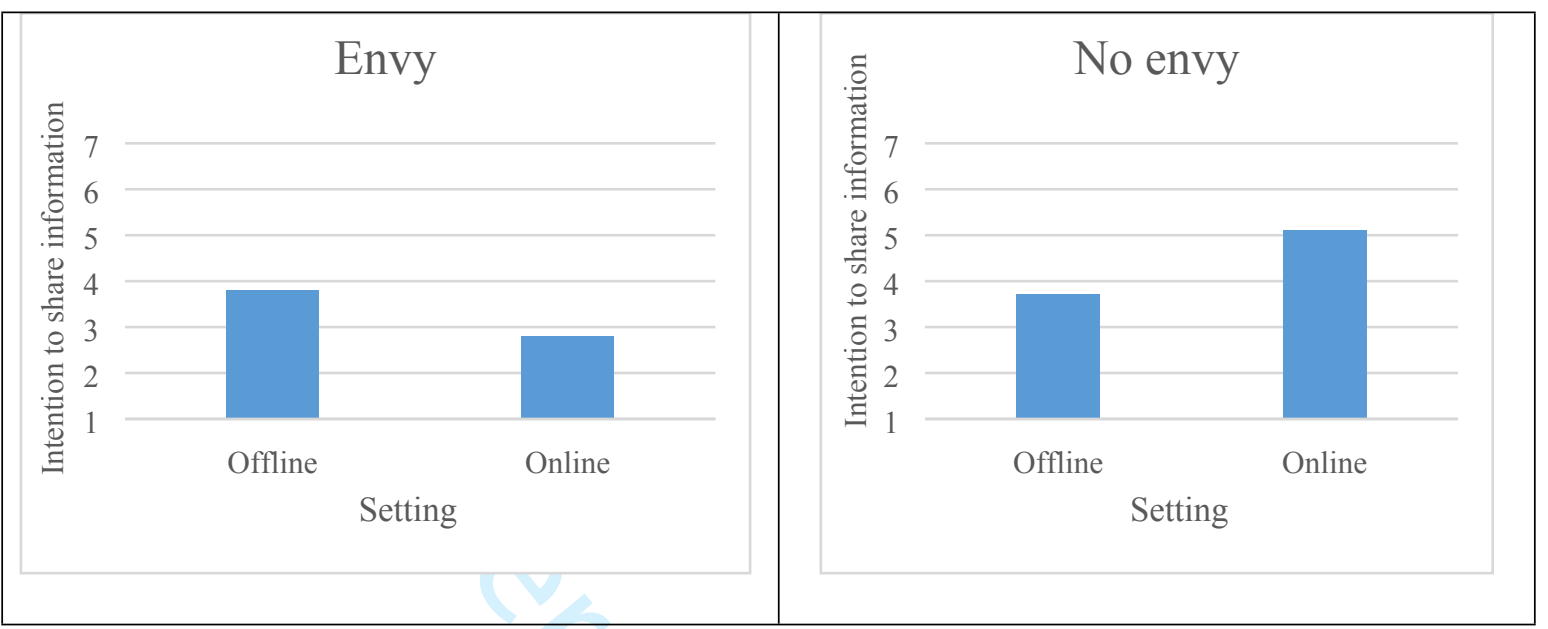


Others' fortune in online vs. offline settings: how envy affects people's intention to share information

\section{Purpose}

This paper fills a gap in the existing literature by answering the following question: is the effect of envy on people's intention to share information the same in offline settings and on online social networks?

\section{Methodology}

Two studies demonstrate (1) how envy that results from upward social comparisons affects people's intention to share information and (2) the difference between online and offline settings.

\section{Findings}

The likelihood of sharing information susceptible of triggering envy is lower on online social networks than in an offline scenario.

\section{Research implications}

In digital environments, feelings of envy depend on the number of social comparisons that the individual is exposed to.

\section{Practical implications}

This research recommends (a) incorporating tools that allow online social network users to feel part of their network's successes, (b) promoting offline diffusion of information, and (c) encouraging people to play an active role when using online social networks.

\section{Social implications}

Benefits can be derived from offering tools that permit receivers to take advantage of the selective self-presentation of other users. Such tools could have positive consequences for the welfare of online social network users.

\section{Originality}

To date, the literature has paid no attention to envy as an engine of information sharing. This aspect is especially relevant when discussing platforms whose main goal is precisely information sharing and that offer fertile ground for upward social comparisons.

\section{Keywords}

Online social networks, word-of-mouth, emotions, envy

\section{Article classification}

Research paper 
Others' fortune in online vs. offline settings: how envy affects people's intention to share information

\begin{abstract}
"Well, I think everybody just wants to share their best moments and accomplishments. It is so rare to see posts like 'I just failed my test' or 'I lost my job'... Either way, no matter if she is happy or sad, no matter how she feels in this post, she is comparing her life."
\end{abstract}

(Focus group excerpt $)^{1}$

\title{
1. Introduction
}

A constant element in online social networks (OSNs) is the presence of social comparisons. OSNs work as showcases for picture-perfect aspects of other people's lives (Lemay et al., 2019), such as a recent trip, a smiling portrait with the family, a wonderful meal in an amazing restaurant, a sporting achievement, etc. A distinctive characteristic of OSNs is precisely that users make a conscious effort of selective self-presentation (Chou and Edge, 2012); that is, they carefully choose which aspects of their lives to emphasize (Gonzales and Hancock, 2011). As a consequence, OSNs can be considered nests of narcissism (Wells and Dennis, 2016). Different tools for impression management—friends' acceptance/rejection, the cover picture,

\footnotetext{
${ }^{1}$ The authors would like to thank the students of the American Marketing Association collegiate chapter at the University of Maryland's Robert H. Smith School of Business for their kind participation in the focus groups in the early stages of this research.
} 
and the photos displayed - are available on platforms such as Facebook and Instagram (Amichai-Hamburger and Vinitzky, 2010). These spaces are "rooms of mirrors" where the receiver uses the best-possible image of many senders as a gauge for self-evaluation. All of these features convert OSNs into "upward social comparison-rich environments" that may easily stimulate envy" (Wallace et al., 2017, p. 54).

Although research has recently started to emphasize the emotional reactions of OSN users (Kross et al., 2013; Lin et al., 2014), the literature on the specific influence of envy is scarce (Wenninger et al., 2019; Jin and Ryu, 2020). The few studies about OSNs and envy focus on the undesirable consequences of envy provoked by social information consumption. This previous research has found that OSN consumption affects both users' lives and their selfperceptions (Chou and Edge, 2012; Appel et al., 2015). For example, Krasnova et al. (2015) reported that social media participation can be associated with lower levels of cognitive and affective well-being. In the same way, Lemay et al. (2019) also concluded that envy on OSNs negatively influences subjective well-being. Tandoc et al. (2015) contributed to the stream of research that defends an OSN-depression link by pointing out that this relationship is mediated by feelings of envy. Furthermore, it has been shown that the relationship between OSN use and envy is affected by user personality traits and by user uses and gratifications (Wallace et al., 2017). This previous research has made significant headway in explaining the likelihood of envy arising on OSNs. However, there is a lack of understanding of the responses to envy in social media settings (Wenninger et al., 2019), that is, how users cope with self-discomfort following a situation characterized by multiple upward social comparisons. This study considers, among various reactions of enviers to their envious feelings, how envy affects people's sharing of information (i.e., word-of-mouth). Indeed, it has been demonstrated that envy provokes a tendency to level the difference between the self and the envied person (Lange 
et al., 2018). This paper suggests that this leveling process should have an effect on the intention of people to share information that causes envy. The relevance of this possible reaction to envy rests on the essential role that sharing information plays in the scalability and spread that online platforms make possible (Cheung and Lee, 2012). Actually, "large-scale sharing is one of the most prominent social phenomena of the $21^{\text {st }}$ century, with roots in the oldest form of communication" (Scholz et al., 2017, p. 2881). Word-of-mouth is the mostrepresented topic in digital and social marketing research (Stephen, 2016). The ease with which customers can share information is one of the main differences between traditional and digital marketing environments (Kannan and Li, 2017). In fact, the barriers in terms of the cost of the technical infrastructure required to reach large numbers of people that characterized information diffusion in the pre-OSN era no longer exist (Stieglitz and Dang-Xuan, 2013). A better understanding of information sharing as a response to envy may be useful for helping OSN users maintain an optimal state of well-being. Thus, this research may help us understand the emotional outcomes of reading posts on OSNs (Lin and Utz, 2015) and be conscious of the impact of perceptions of others' lives (Chou and Edge, 2012). It can be crucial to comprehend the reach of information available in an online setting (Cappella et al., 2015). In addition, clarifying the relationship between envy and information sharing can contribute to shedding light on the differences in the drivers of online and offline word-of-mouth, a central issue in the study of how interpersonal influence occurs (Berger and Schwartz, 2011).

Our study aims to contribute to the existing body of literature in two primary ways: (1) by exploring the influence of envy provoked by upward social comparisons on people's intention to share information and (2) by comparing this influence in offline (i.e., face-to-face) vs. OSN contexts. In this way, we fill a gap in the existing literature by answering the following 
question: is the effect of envy on people's intention to share information the same offline and on OSNs?

We conducted two studies based on experimental designs to show the effect of envy on people's intention to share information in an offline vs. an OSN setting (Study 1) and to demonstrate how envy provoked by upward social comparisons affects people's intention to share information on OSNs (Study 2).

The paper is organized as follows. In Section 2, we present the framework that defines key concepts in the context of this research, and we discuss previous works on information sharing and envy. We then describe the methodology and present the data analysis and results of the two studies in Section 3. The research and managerial implications are discussed in Section 4, where we also assess the limitations of the paper and highlight future research opportunities. Finally, we conclude the research in Section 5.

\section{Theoretical Background}

Information sharing has long been recognized as a significant nonmarketer-dominated purchase influence (Dichter, 1966). It was more than three decades ago that the initial conception of the influence of opinion leaders on consumers was extended to all types of "informal communications directed at other consumers about the ownership, usage, or characteristics of particular goods and services and/or their sellers" (Westbrook, 1987, p. 261). For instance, users can generate post-purchase information transmission (i.e., word-of-mouth) through a simple conversation with someone about a consumption experience or through interpersonal communication via Facebook, Twitter, YouTube or other OSNs. 
Research on word-of-mouth initially focused more on its impact than on its drivers (Berger and Schwartz, 2011). However, the emergence of OSNs and the subsequent simplification of information sharing have provoked growing interest in the motives behind word-of-mouth. Factors that drive information transmission are now being analyzed in both research on psychological motivations and research on message characteristics. For example, studies have analyzed how people transmit information that positively affects their interpersonal relations (e.g., Chen, 2017), which is a psychological motivation, and how people transmit information that is seen as high in utility (e.g., Moldovan et al., 2011), which is a message characteristic. Notwithstanding their apparent disparity, these two approaches are complementary, since the impact of message features is the result of how they enhance or impair psychological motivations (Cappella et al., 2015). Thus, Berger (2014) argued that there are five key functions that drive word-of-mouth, namely, impression management, emotion regulation, information acquisition, social bonding, and persuasion. Of all of these functions, emotion regulation is particularly relevant in the context of this research. Emotion regulation refers to the "processes by which individuals influence which emotions they have, when they have them, and how they experience and express these emotions" (Gross, 1998, p. 275). Research has demonstrated that the affective burden of messages influences information sharing (Berger and Milkman, 2012) in terms of both quantity and speed (Stieglitz and Dang-Xuan, 2013). Information sharing can amplify the effect of positive emotions or mitigate the effect of negative emotions (Berger, 2014). However, there are contexts in which the role of emotion in information sharing is more complex. This is the case in situations where feelings of envy come into play. Emotions such as shame and guilt have been highlighted as deterrents of information sharing (Finkenauer and Rimé, 1998), but the effect of envy on information sharing has received little attention (Suárez et al., 2020). Frenzen and Nakamoto (1993) originally 
identified the possible existence of "psychic costs" — as differentiated from economic costsof information sharing. These authors mentioned embarrassment or shame as psychic costs associated with revealing information that bears a social stigma.

\subsection{Envy}

Envy is considered a negative emotion that necessarily involves at least two individuals, specifically, the envied and the envier (Laros and Steenkamp, 2005). Although envy is a universal human characteristic, it is the least confessable emotional impulse for individuals (Foster et al., 1972). In the specific context of OSNs, Krasnova et al. (2013) found that feelings of envy are very common, especially in the case of users who engage in passive behavior when browsing.

Envy occurs “when a person lacks another's superior quality, achievement, or possession and either desires it or wishes that the other lacked it" (Parrott and Smith 1993, p. 906). As envy is an emotion that has a negative valence that generates feelings of displeasure and pain (Lieberman and Eisenberger, 2008), people develop mechanisms to cope with its uncomfortable effects (Van de Ven et al., 2010). Possible responses range from motivation for self-improvement, which is considered a benign form of envy that makes people feel better about themselves, to demoralization, which is proper or malicious envy characterized by feelings of inferiority and frustration (Wobker and Kenning, 2013). Recent research in the envy domain concludes that both benign and malicious envy that follow a status comparison have socially undesirable elements (Lange et al., 2018). Filling the gap with the envied other can mean pulling him or her down. In its worst version, envy is accompanied by expressions of 
hostility that contradict the social norm of being happy about other people's success (Heider, 1958). Thus, the uncomfortableness of envy comes from the perception of inferiority and from the shame associated with feeling in such a way (Smith, 2004). This paper focuses on how the tendency to share information can be affected by the response of the envious to the discomfort provoked by their unpleasant feelings of envy.

\subsection{The effect of envy on information sharing}

Emotional experiences have interpersonal consequences (Rimé, 2009). In fact, emotions are "the major currency in which social intercourse is transacted" (Zajonc, 1980, p. 153). Schachter (1959) demonstrated that negative emotions stimulate information sharing due to the anxietybuffering function of social relationships (Bowlby, 1982). Similarly, positive emotions can also be seen as an opening of social communication (Fredrickson, 2000). Langston (1994) commented that a process of capitalization of positive emotions can occur when people derive associated benefits from sharing those positive emotions. One of the mechanisms for such an effect is that social sharing builds social resources by fostering positive social interactions (Gable et al., 2004).

The literature has seen an enormous growth in research on emotions and social sharing in recent years. A large part of this explosive growth has been the documentation of the phenomenon of mainstream adoption of social media and the development of theories and models related to the connection between emotions and information sharing through OSNs (e.g., Stieglitz and Dang-Xuan, 2013). These studies rest on the fact that social media as a data source allow us to explore people's feelings (Dodds et al., 2011). Currently, a growing number of studies are trying to assess how people subjectively feel by taking into account what they post on OSNs 
(Kross et al., 2013). Despite this relevance of emotions as drivers of information sharing through OSNs, there are exceptions to this dynamic. When people experience self-conscious emotions, such as envy, they generally avoid sharing these experiences with others (Bagozzi, 2006; Rimé, 2009; Salerno et al., 2019). Envy always results from a self-evaluative process (Tracy and Robins, 2004), and social comparisons are a mechanism that can affect selfevaluation (Tesser, 2000). One perspective of particular usefulness in recognizing the influence of social comparisons on self-evaluation is the self-evaluation maintenance model (Tesser et al.,1988). This model predicts that the outstanding performance of others instigates changes in self-evaluation. Evaluation can be threatened via comparison or can be augmented via reflection. To reduce a threat to self-esteem or to augment self-esteem, individuals try to distort beliefs about relative performance (Salovey and Rodin, 1988; Tesser, 2000). Individuals will be motivated to share information about others' better performance when the individuals can "bask in the reflected glory" (Tesser et al., 1988, p. 49) and, therefore, raise their selfevaluation through the reflection process. In contrast, when the outstanding performance of others results in a loss of self-evaluation through the comparison process, individuals will not be motivated to socially share others' good performance. Previous empirical findings (De Angelis et al., 2012) have shown that sharing information on others' negative consumption experiences responds to a basic human motive to self-enhance. We propose that not sharing others' positive consumption experiences that are a source of envy is also a way to maintain self-esteem.

\section{Proposal and Analysis of the Results}

This research investigates how envy derived from upward social comparisons affects information sharing. Previous studies have identified consumer envy as a driver of negative 
interpersonal communication (Wobker and Kenning, 2012). We suggest that when envy is the result of information shared through OSNs, it can also deter information sharing. In terms of the previously mentioned self-evaluation maintenance model (Tesser et al.,1988) (Section 2.2), our intuition is that in an environment characterized by overexposure to others' better performance, comparison prevails over reflection as a mechanism to cope with the effect of social comparisons on self-evaluation. With the exception of Krasnova et al. (2013) and Wenninger et al. (2019), the literature lacks research into how individuals cope with envy on OSNs. Our proposal is that withheld word-of-mouth information could also be used to address feelings of envy. Not sharing information limits the adverse effect on self-evaluation of the comparison with others' good performance. In contrast, sharing information about others' good performance augments the threat posed by this information to one's self-evaluation.

We present two studies (see Table 1 for a study overview) to demonstrate (1) how envy that results from upward social comparisons affects people's intention to share information and (2) how this effect differs in online and offline contexts. Study 1 examines how enviers respond to their envious feelings in terms of their intention to share information. Study 2 uses a multi-item OSN-situational envy scale based on previous literature to capture individuals' envy and focus on the influence of envy on information sharing, specifically in the online context. The participants in all the experiments were undergraduate students from a European university. An entirely new set of students was used in each of the two studies. Participation was in all cases in partial fulfillment of a course requirement. The adequacy of the samples of students in this context was justified by previous research (Sun et al., 2006; Appel et al., 2016).

\section{INSERT TABLE 1 ABOUT HERE}




\section{$3.1 \quad$ Study 1}

The main goal of Study 1 was to analyze how enviers cope with their envious feelings in terms of their intention to share information in offline and online settings. We gave the participants one of four different scenarios. These four scenarios were built by crossing the two factors of envy and setting. The study had a 2 (envy: envy or no envy) $\times 2$ (setting: online or offline) between-subjects design. We asked the participants about their intention to share the information described in the scenario.

Our prediction is that the intention to share information that may elicit envy is lower in an online setting than in an offline setting.

Method. One hundred and ninety-two respondents (56.3\% female, mean age $=22$ years $)$ participated in an experimental design with two levels of envy (envy or no envy) and two settings (offline or online). Each participant was exposed to only one of the two envy and setting levels.

The participants were emailed a link to complete the experiment online. They received a description of one of the four scenarios (see Study 1 scenarios in the Appendix). All scenarios referred to hypothetical communication with another person. We adapted a procedure used in word-of-mouth studies based on hypothetical consumption experiences (Wojnicki and Godes, 2008) to analyze social interaction situations. Additionally, in accordance with previous literature (Moran and Schweitzer, 2008), we matched the gender of the participant with the gender of the other person involved in the social interaction. Furthermore, given the role of 
similarity in feelings of envy (Smith, 2004), we designed Study 1 so that the two people involved in the social interaction were classmates.

In the offline condition, the participants imagined running into a classmate who recently purchased the same mobile phone as the participant. In the online condition, the participants were supposed to open their Facebook page and imagine that they had received five different posts on their Facebook wall on one imaginary morning. In the envy condition, the first four posts were based on the description of Krasnova et al. (2013) of envy-provoking domains on Facebook and on previous exploratory research and referred to news about classmates in a manner likely to trigger upward social comparisons. The last post was related to the purchase of a mobile phone. Mobile phones are conspicuous products and have been considered by previous research in the social comparison domain (Berger and Schwartz, 2011). In the noenvy condition, the posts contained "plain" information not likely to trigger a social comparison and one last post about the purchase of a mobile phone. In the no-envy condition, the mobile phone was the same as the mobile phone of the participant. In the envy condition, the mobile phone was also the same as that of the participant but was purchased with a significant price cut. Comparisons with friends who find special bargains for the same product are likely to elicit envy (Ackerman and Perner, 2004). In fact, in a pretest $(\mathrm{N}=82)$ the participants rated the perceived level of envy of each condition on a 7-point scale. Pairedsample tests confirmed that there were statistically significant differences between the levels of perceived envy in each scenario (Moffline_no envy=2.3, Moffline_envy=4.5; $\mathrm{t}=-11.4, \mathrm{p}<0.00$; Monline_no envy=2.7, Monline_envy=4.3; $\mathrm{t}=-7.4, \mathrm{p}<0.00)$.

The participants were asked how likely (on a scale from $1=$ not at all to $7=$ extremely) they would be to share their classmate's consumption experience. A similar dependent variable has been used by previous studies in the word-of-mouth field (Barasch and Berger, 2014). 
Results. We analyze the data using a two-way ANOVA in which the likelihood of information sharing was expressed as a function of envy (envy/no envy), setting (online/offline) and their interaction. A Levene test (Levene, 1960, Conover et al., 1981) was used to test the hypothesis of equal variances in all treatments $(F(3,188)=1.31, p=0.27)$. A significant main effect of envy emerged $(F(1,192)=21.3, p<0.00)$, suggesting that the likelihood of information sharing is lower when the message conveys information able to elicit envy $(M=3.2, S D=1.8)$ than when the message conveys neutral information $(M=4.4, S D=$ 1.8). There is no significant effect of setting $(F(1,192)=0.08, p>0.5)$. The main effect of envy was qualified by a two-way interaction between envy and setting $(F(1,192)=28.8, p<0.00)$. As shown in Figure 1, in the envy condition, the probability of sharing information is higher offline than online (Menvy_offline=3.8, Menvy_online=2.6). Similarly, the probability of sharing information in the no-envy condition is higher online than offline (Mno_envy_offline= 3.7, Mno_envy_online= 5.1).

\section{INSERT FIGURE 1 ABOUT HERE}

These findings underscore our predictions of the different effects of envy on information sharing and of the differences in offline and online settings.

\subsection{Study 2}


Study 2 was designed to extend the previous study by incorporating a scale capturing an individual's envy instead of the one-item measure used in Study 1. Study 1 demonstrated that overexposure to unfavorable social comparisons diminishes the likelihood of transmitting others' positive news. Additionally, in this second study, we searched for further evidence for our perspective, focusing on the online setting.

Method. We conducted an online survey with one hundred and thirty-four participants, all of whom were familiar with Instagram ${ }^{2}(\mathrm{~N}=134,67.9 \%$ female, mean age $=21.6$ years $)$. Before the study, a filtering question checked the eligibility of the respondents, namely that they were regular Instagram users.

The participants were informed that they would take part in two different studies on the use of OSNs as communication media. They first completed a recall task designed to manipulate envy. The participants assigned to the envy condition received the following instructions: "Please recall a situation where you were on Instagram and found many posts from the people you follow in situations that proved that they were doing great, much better than you (for instance, pictures of an amazing trip, gatherings with friends in cool restaurants, new job positions...). Think how you felt after seeing those posts." The participants in the no-envy condition, in contrast, were given the following instructions: "Please recall a situation in which you were on Instagram and you found many posts from people you follow in situations that showed that they were not doing so well or actually doing worse than you. Think how you felt after seeing those posts." The participants were randomly assigned to the two conditions. Previous studies have shown that recalling a certain situation in which emotions are felt activates the action tendencies of these emotions (Malatesta and Izard, 1984; Strack et al., 1985). In the specific context of social comparisons, this recall method has been used by

\footnotetext{
${ }^{2}$ In a pilot study, we identified Instagram as the most popular OSN among the student population.
} 
previous studies (i.e., Van de Ven et al., 2011; Rentzsch and Gross, 2015; Lange et al., 2018). After recalling the experience, the participants responded to a five-item Instagram situationalenvy measure on seven-point Likert scales ( $1=$ strongly disagree to $7=$ strongly agree $)$. The Instagram situational-envy scale was derived from the multi-item self-reported scale of the Facebook situational-envy scale proposed by Wallace et al. (2017).

Next, the questionnaire guided the respondents through an ostensibly unrelated study, in which they had to imagine that one of the brands they regularly follow posted the results of a competition in which the student had participated. The winner of the competition turned out to be another student. The criterion for selecting the winner was excellence in school grades. The description of the stimulus was adapted from previous studies (Van de Ven et al., 2011). The participants were asked to rate how likely they would be to share the post with the competition's result on a seven-point scale ( $1=$ very unlikely to $7=$ very likely).

Results. We computed the average value of the five items of the Instagram situationalenvy scale to obtain an index $(\alpha=0.91, \mathrm{M}=4.0, \mathrm{SD}=1.7)$. A manipulation check confirmed that the participants who recalled unfavorable social comparisons showed higher levels of Instagram situational envy than the participants who recalled favorable social comparisons $\left(\mathrm{M}_{\text {unfavorable social comparisons }}=4.6\right.$ vs. $\left.\mathrm{M}_{\text {favorable social comparisons }} ; 3.4 \mathrm{t}(132)=4.0, \mathrm{p}<.00\right)$.

As we predicted, compared with the participants' willingness to share information in the noenvy situation $(M=2.9)$, exposure to information likely to elicit envy on OSNs led the participants to decrease their willingness to share posts related to others' outperformance $(\mathrm{M}=$ 2.0). The average values of willingness to share were compared by using the modification of 
the two-sample t-test (Montgomery, 2019) proposed for cases where the assumption of equal variances may not be appropriate $(\mathrm{t}(110.7)=-3.2, \mathrm{p}<0.00)$.

\section{General Discussion}

The recent literature on OSNs indicates that exposure to these platforms may trigger envy. Envy is a very powerful emotion from an economic perspective. Its role as a consumption promoter has been greatly analyzed. However, less attention has been paid to envy as an engine of information sharing. This aspect is especially relevant when discussing platforms whose main goal is precisely information sharing and that offer fertile ground for upward social comparisons.

In the current research, two experiments demonstrate how envy derived from upward social comparisons affects information sharing. Relative to an offline scenario, the likelihood of sharing information susceptible to triggering envy is lower on OSNs (Study 1). On OSNs, when individuals are overexposed to others' better performance, they are not motivated to transmit others' positive news that threatens their self-evaluation (Study 2).

\subsection{Contribution}

Our findings yield three main contributions. Firstly, they provide insight into the influence of envy on information sharing through OSNs. It has been pointed out in recent research that browsing OSNs can induce a depressed mood due to the envy triggered by unflattering social comparisons (Krasnova et al., 2013; Lin and Utz, 2015). It has also been shown that this negative effect on well-being seems to be particularly intense with passive use of these 
platforms (Appel et al., 2016). To the best of our knowledge, no previous research has considered the negative effects associated not only with browsing but also with socially transmitting other people's positive information. We have filled this gap by showing that sharing other people's good news received through settings that favor multiple, public upward social comparisons - as in the case of OSNs - entails a cost derived from the envy experienced, and this cost does not seem to exist in the case of one-to-one communication.

Secondly, this article demonstrates that in terms of emotional experience, receiving an unflattering comparison over OSNs differs considerably from obtaining this information through a face-to-face encounter. The reason seems to be that the unflattering comparison is one of many that the receiver confronts, which creates a heavy emotional burden. Previous research has investigated the difference between sharing information when talking to only one person versus talking to two or more people (Barasch and Berger, 2014). Our study adopts the point of view of the receiver. We have shown that in the same way that the number of receivers influences what people discuss, the number of posters also affects the reader's inclination to share the received information.

Lastly, envy has been considered an "ancient psychological mechanism that remains part of human behavior even in modern times..." (Wobker and Kenning, 2013, p. 191). Researchers have discussed the relationship between envy and factors such as the subjective fairness of the advantage of the other person, the attainability of the other person's accomplishment, the selfrelevance and self-definition of the domain of the comparison, the perceived ability to change the envy-eliciting advantage, and the lack of superiority in alternative comparison domains (Parrott and Smith, 1993; Lockwood and Kunda, 1997; Smith, 2004; Van de Ven et al., 2010). Our research identifies that in digital environments, an additional factor should be considered: 
the number of social comparisons that the individual is exposed to. Overexposure to others' better performance threatens individuals' self-evaluation. Our findings help illuminate how multiple, public social comparisons affect people's intention to share information.

\subsection{Implications}

A condition for inspiring consumption by aspirational motives is the diffusion of information related to purchase/use experiences. OSNs offer an ideal medium for spreading this type of information. To leverage the consumption-by-assimilation mechanism, companies should encourage customers to post photos or comments that show their good experiences as a way of both increasing the ego of consumers and eliciting envy among viewers. However, this work emphasizes the dark side of this behavior. Exposure to a multitude of upward social comparisons generates feelings of envy that can deter the online sharing of information. Incorporating tools that allow OSN users to feel part of their network's successes-e.g., photo calls that include integrative messages such as "the only thing missing is you" — or the offline diffusion of information-e.g., promotional objects that can be used in daily life and that encourage the sharing of a consumption experience — can be useful in overcoming the costs of sharing information in online settings. Mui (1995) showed that in an economic system, strategic and not necessarily altruistic reasons can justify success sharing. Anecdotal evidence and empirical studies have shown that the fear of being envied increases prosocial behavior (Van de Ven et al., 2010). In an environment characterized by a high propensity for envy, such as that of OSNs, one way to deal with the threat of envious refusal to share brand messages or consumer experiences may be to redistribute part of the success of companies or consumers toward those who are left behind. 
Our results show that the emotional burden of spreading other people's happiness occurs in contexts in which the receiver passively observes a multitude of unfavorable social comparisons. Encouraging people to assume a more active role when using OSNs should increase their disposition to publicly transmit other people's positive news.

Our results also have significant implications for improving the display of OSNs. The findings suggest that the benefits that could be derived from offering tools to reflect others' good news could boost users' self-evaluation. Such tools could transform the good fortune of others into individuals' own good fortune. Our research suggests that OSNs should promote tools that permit companies to manage consumers' envy through the creation of a strong brand-consumer and consumer-to-consumer sense of belonging. Diffusing other people's positive news could be a way of obtaining "social currency" (Hughes, 2005). By allowing the development of an “augmented self" through selective self-presentation tools, spreading information about others' good fortune could benefit the forwarder. This could also have positive consequences for the welfare of OSN users.

\subsection{Limitations}

Some limitations should be considered and may be useful for planning future avenues of research. First, we used a different number of messages in Study 1 to manipulate the online/offline setting. The rationale for this procedure was to recreate the differences in the comparison triggering information of both contexts. One distinctive characteristic of OSNs is that they offer constant access to social comparison information (Wallace et al., 2017). Li and $\mathrm{Du}$ (2017) studied differences in the effectiveness of message dissemination between online and offline contexts, developing a simulation system. They concluded that one main difference 
between these settings is the factor that we considered, namely, the amount of information due to the number of connections. However, these authors also signaled differences in terms of the degree of intimacy of offline/OSNs, diversity of users' backgrounds and the cost of message distribution. Accordingly, further research is needed to manipulate the number of messages as a separate factor, ascertaining if it is the number of messages or other online-specific factors that interact with the information-impeding effect of envy.

A second caveat concerns our use of experimental studies, which entails limitations in terms of external validity. It would be very interesting to employ a multimethod approach by combining experimental studies with field data.

Our studies chose student samples. University students are a homogeneous group that has been used as a sample in numerous studies (Zhang et al., 2020). However, the characteristics of this sample may limit the generalizability of the results. Future research could test our findings with other demographic segments. Additionally, recent research has investigated how culture affects behavioral strategies to reduce envy in the OSN context (Wenninger et al., 2019). Crosscountry studies in the future can address the possible influence of cultural values on social comparisons (Loureiro et al., 2020) and their effect on information sharing.

Our research offers evidence on how envy influences people's intention to share information. However, we did not consider the effect of envy on actual behavior. In the real world, a difference between intention and behavior could exist, for example, in situations where OSN users feel social pressure to share the information. Investigating whether people share what they truly want to share offers a worthwhile future research line. 
Finally, further research could investigate how the interpersonal closeness between the envied party and the envier influences people's intention to share information. One might wonder whether the closeness of the relationship between the parties involved in a social interaction affects the costs of information sharing. Indeed, it could be argued that interpersonal closeness may smooth the influence of envy on the likelihood of sharing information on others' good fortune.

\section{Conclusion}

In conclusion, feelings of envy are frequent in OSNs. This paper provides an answer for the question of how those feelings stemming from upward social comparisons on OSNs affect users' intention to share information. Building off the idea that the effect of upward social comparisons on self-evaluation may differ in online and offline contexts, Study 1 and Study 2 show that there is a deterrent effect of envy on information sharing that is more intense in contexts characterized by multiple social comparisons, such as OSNs.

\section{Acknowledgments}

The authors would like to thank the members of the Behavioral Laboratory of the Robert H. Smith School of Business of the University of Maryland for stimulating the germ of this work. Preliminary ideas for this project were presented at the Association for Consumer Research Conference 2016 (http://www.acrwebsite.org/volumes/1022029/volumes/v44/NA44). The useful suggestions of the editor and review team are acknowledged. 


\section{References}

Ackerman, D. S. and Perner, L. (2004), "Did you hear what my friend paid! Examining the consequences of social comparisons of prices”, in Kahn, B. E., \& Luce, M.F. (Ed.s), NA-Advances in Consumer Research 2004, Valdosta, GA, pp.586-592.

Amichai-Hamburger, Y. and Vinitzky, G. (2010), "Social network use and personality", Computers in Human Behavior, Vol. 26 No. 6, pp.1289-1295. https://doi.org/10.1016/j.chb.2010.03.018

Appel, H., Crusius, J. and Gerlach, A.L. (2015), "Social comparison, envy, and depression on Facebook: a study looking at the effects of high comparison standards on depressed individuals," Journal of Social and Clinical Psychology, Vol. 34 No. 4, pp.277-289. https://doi.org/10.1521/jscp.2015.34.4.277

De Angelis, M., Bonezzi, A., Peluso, A. M., Rucker, D. D. and Costabile, M. (2012), “On braggarts and gossips: A self-enhancement account of word-of-mouth generation and transmission", Journal of Marketing Research, Vol. 49 No. 4, pp.551-563. https://doi.org/10.1509\%2Fjmr.11.0136

Appel, H., Gerlach, A. L. and Crusius, J. (2016), “The interplay between Facebook use, social comparison, envy, and depression", Current Opinion in Psychology, Vol. 9, pp.44-49. https://doi.org/10.1016/j.copsyc.2015.10.006

Bagozzi, R. P. (2006), “The role of social and self-conscious emotions in the regulation of business-to-business relationships in salesperson-customer interactions", The Journal of Business and Industrial Marketing, Vol. 21 No. 7, pp.453-457. https://doi.org/10.1108/08858620610708948 
Barasch, A. and Berger, J. (2014), "Broadcasting and narrowcasting: How audience size affects what people share", Journal of Marketing Research, Vol. 51 No. 3, pp.286-299. https://doi.org/10.1509\%2Fjmr.13.0238

Berger, J. (2014), "Word of mouth and interpersonal communication: A review and directions for future research", Journal of Consumer Psychology, Vol. 24 No. 4, pp.586-607. https://doi.org/10.1016/j.jcps.2014.05.002

Berger, J. and Milkman, K. L. (2012), “What makes online content viral?”, Journal of Marketing Research, Vol. $49 \quad$ No. 2, pp.192-205. https://doi.org/10.1509\%2Fjmr.10.0353

Berger, J. and Schwartz, E. M. (2011), “What drives immediate and ongoing word of mouth?”, Journal of Marketing Research, Vol. 48 No. 5, pp.869-880. https://doi.org/10.1509\%2Fjmkr.48.5.869

Bowlby, J. (1982), “Attachment and loss: retrospect and prospect”, American Journal of $\begin{array}{lllll}\text { Orthopsychiatry, } & \text { Vol. } & 52 & \text { No. } & 4,\end{array}$ https://psycnet.apa.org/doi/10.1111/j.1939-0025.1982.tb01456.x

Cappella, J. N., Kim, H. S. and Albarracín, D. (2015), "Selection and transmission processes for information in the emerging media environment: Psychological motives and message characteristics", Media Psychology, Vol. 18 No. 3, pp.396-424. https://doi.org/10.1080/15213269.2014.941112

Chen, Z. (2017), "Social acceptance and word of mouth: How the motive to belong leads to divergent WOM with strangers and friends", Journal of Consumer Research, Vol. 44 No. 3, pp.613-632. https://doi.org/10.1093/jcr/ucx055

Cheung, C. M. and Lee, M. K. (2012), "What drives consumers to spread electronic word of mouth in online consumer-opinion platforms", Decision Support Systems, Vol. 53 No. 1, pp.218-225. https://doi.org/10.1016/j.dss.2012.01.015 
Chou, H. T. G. and Edge, N. (2012), “"They are happier and having better lives than I am": the impact of using Facebook on perceptions of others' lives”. Cyberpsychology, Behavior, and Social Networking, Vol. 15 No. 2, pp.117-121. https://doi.org/10.1089/cyber.2011.0324

Conover, W. J., Johnson M. E. and Johnson M. M. (1981), “A comparative study of tests for homogeneity of variances, with applications to the outer continental shelf bidding data", $\begin{array}{lllll}\text { Technometrics, } & \text { Vol. } & 23 & \text { No. } & 4,\end{array}$ https://doi.org/10.1080/00401706.1981.10487680

Dichter, E. A. (1966), "How word of mouth advertising works", Harvard Business Review, Vol. 44 November-December, pp.147-57.

Dodds, P. S., Harris, K. D., Kloumann, I. M., Bliss, C. A. and Danforth, C. M. (2011), "Temporal patterns of happiness and information in a global social network: hedonometrics and Twitter", PloS one, Vol. 6 No. 12, e26752. https://doi.org/10.1371/journal.pone.0026752

Finkenauer, C. and Rimé, B. (1998), “Socially shared emotional experiences vs. emotional experiences kept secret: differential characteristics and consequences", Journal of Social and Clinical Psychology, Vol. 17 No. 3, pp.295-318. https://doi.org/10.1521/jscp.1998.17.3.295

Foster, G. M., Apthorpe, R. J., Bernard, H. R., Bock, B., Brogger, J., Brown, J. K., Cappannari, S. C., Cuisenier, J., D'Andrade, R. G., Faris, J., Freeman, S. T., Kolenda, P., MacCoby, M., Messing, S. D., Moreno-Navarro, I., Paddock, J., Reynolds, H. R., Ritchie, J. E., St. Erlich, V., Saviahinsky, J. S., Seddon, J.D., Utley, F. L. and Whiting, B. B. (1972), "The anatomy of envy: A study in symbolic behavior [and comments and reply]", Current Anthropology, Vol. 13 No. 2, pp.165-202. https://doi.org/10.1086/201267 
Fredrickson, B. L. (2000), “Cultivating positive emotions to optimize health and well-being”, Prevention \& Treatment, Vol. 3 No. 1, Article 1. https://psycnet.apa.org/doi/10.1037/1522-3736.3.1.31a

Frenzen, J. and Nakamoto, K. (1993), "Structure, cooperation, and the flow of market information", Journal of Consumer Research, Vol. 20 No. 3, pp.360-375. https://doi.org/10.1086/209355

Gable, S. L., Reis, H. T., Impett, E. A. and Asher, E. R. (2004), "What do you do when things go right? The intrapersonal and interpersonal benefits of sharing positive events", Journal of Personality and Social Psychology, Vol. 87 No. 2, pp.228-245. https://psycnet.apa.org/doi/10.1037/0022-3514.87.2.228

Gonzales, A. L. and Hancock, J. T. (2011), “Mirror, mirror on my Facebook wall: Effects of exposure to Facebook on self-esteem", Cyberpsychology, Behavior, and Social Networking, Vol. 14 No.1-2, pp.79-83. https://doi.org/10.1089/cyber.2009.0411

Gross, J. J. (1998), “The emerging field of emotion regulation: An integrative review”, Review of General Psychology, Vol. 2 No. 3, pp.271-299. https://doi.org/10.1037\%2F10892680.2.3.271

Heider, F. (1958), The Psychology of Interpersonal Relations, Psychology Press, London, UK. Hughes, M. (2005), Buzzmarketing, Penguin, New York, NY.

Jin, S. V. and Ryu, E. (2020), ““'I'll buy what she's \# wearing”: the roles of envy toward and parasocial interaction with influencers in Instagram celebrity-based brand endorsement and social commerce”, Journal of Retailing and Consumer Services, Vol. 55, 102121. https://doi.org/10.1016/j.jretconser.2020.102121

Kannan, P. K. and Li, H. A. (2017), "Digital marketing: a framework, review and research agenda", International Journal of Research in Marketing, Vol. 34 No. 1, pp.22-45. https://doi.org/10.1016/j.ijresmar.2016.11.006 
Krasnova, H., Wenninger, H., Widjaja, T. and Buxmann, P. (2013), “Envy on Facebook: a hidden threat to users' life satisfaction?", in 11th International Conference on Wirtschaftsinformatik (WI2013), Universität Leipzig, Germany.

Krasnova, H., Widjaja, T., Buxmann, P., Wenninger, H. and Benbasat, I. (2015), "Research note- - why following friends can hurt you: an exploratory investigation of the effects of envy on social networking sites among college-age users", Information Systems Research, Vol. 26 No. 3, pp.473-636. https://doi.org/10.1287/isre.2015.0588

Kross, E., Verduyn, P., Demiralp, E., Park, J., Lee, D. S., Lin, N., Shablack, H., Jonides, J. and Ybarra, O. (2013), "Facebook use predicts declines in subjective well-being in young adults”, Plos One, Vol. 8 No. 8, e69841. https://doi.org/10.1371/journal.pone.0069841

Lange, J., Paulhus, D. L. and Crusius, J. (2018), "Elucidating the dark side of envy: Distinctive links of benign and malicious envy with dark personalities", Personality and Social Psychology Bulletin, Vol. $44 \quad$ No. $\quad 4, \quad$ pp.601-614. https://doi.org/10.1177\%2F0146167217746340

Langston, C. A. (1994), "Capitalizing on and coping with daily-life events: expressive responses to positive events", Journal of Personality and Social Psychology, Vol. 67 No. 6, pp.1112-1125. https://psycnet.apa.org/doi/10.1037/0022-3514.67.6.1112

Laros, F. J. and Steenkamp, J. B. E. (2005), "Emotions in consumer behavior: a hierarchical approach", Journal of Business Research, Vol. 58 No. 10, pp.1437-1445. https://doi.org/10.1016/j.jbusres.2003.09.013

Lemay, D. J., Doleck, T. and Bazelais, P. (2019), "Do instrumental goal pursuits mediate feelings of envy on Facebook and Happiness or subjective well-being?”, Computers in Human Behavior, Vol. 91, pp.186-191. https://doi.org/10.1016/j.chb.2018.09.043

Levene, H. (1960), "Robust tests for equality of variance”, in Olkin, Z. (Ed.), Contributions to Probability and Statistics, Stanford University Press, Palo Alto, CA, pp.278-292. 
Li, F. and Du, T. C. (2017), “The effectiveness of word of mouth in offline and online social networks", Expert Systems $\quad$ with $\quad$ Applications, Vol. $\quad 88, \quad$ pp.338-351. https://doi.org/10.1016/j.eswa.2017.07.004

Lieberman, M. D. and Eisenberger, N. I. (2008), "The pains and pleasures of social life: a social cognitive neuroscience approach”, NeuroLeadership Journal, Vol. 1, pp.38-43.

Lin, H., Fan, W. and Chau, P. Y. (2014), “Determinants of users' continuance of social networking sites: A self-regulation perspective”, Information and Management, Vol. 51 No. 5, pp.595-603. https://doi.org/10.1016/j.im.2014.03.010

Lin, R. and Utz, S. (2015), “The emotional responses of browsing Facebook: happiness, envy, and the role of tie strength", Computers in Human Behavior, Vol. 52, pp.29-38. https://doi.org/10.1016/j.chb.2015.04.064

Lockwood, P. and Kunda, Z. (1997), "Superstars and me: predicting the impact of role models on the self", Journal of Personality and Social Psychology, Vol. 73 No. 1, pp.91-103. https://psycnet.apa.org/doi/10.1037/0022-3514.73.1.91

Loureiro, S. M. C., de Plaza, M. A. P. and Taghian, M. (2020), "The effect of benign and malicious envies on desire to buy luxury fashion items", Journal of Retailing and Consumer Services, Vol. 52, 101688. https://doi.org/10.1016/j.jretconser.2018.10.005

Malatesta, C. Z. and Izard, C. E. (1984), “The facial expression of emotion: Young, middleaged, and older adult expressions", in Malatesta, C.Z. and Izard, C.E. (Ed.s), Emotion in Adult Development, Sage, Beverly Hills, CA, pp.253-273.

Moldovan, S., Goldenberg, J., and Chattopadhyay, A. (2011), "The different roles of product originality and usefulness in generating word-of-mouth", International Journal of Research in Marketing, Vol. $28 \quad$ No. 2, pp.109-119. https://doi.org/10.1016/j.ijresmar.2010.11.003 
Montgomery, D. C. (2019). Design and Analysis of Experiments, 10th edition. John Wiley \& Sons, Inc, New York, NY.

Moran, S. and Schweitzer, M. E. (2008), "When better is worse: Envy and the use of deception", Negotiation and Conflict Management Research, Vol. 1 No. 1, pp.3-29. https://doi.org/10.1111/j.1750-4716.2007.00002.x

Mui, V. L. (1995), “The economics of envy”, Journal of Economic Behavior \& Organization, Vol. 26 No. 3, pp.311-336. https://doi.org/10.1016/0167-2681(94)00079-T

Parrott, W. G. and Smith, R. H. (1993), "Distinguishing the experiences of envy and jealousy", Journal of Personality and Social Psychology, Vol. 64 No. 6, pp.906-920. https://psycnet.apa.org/doi/10.1037/0022-3514.64.6.906

Rentzsch, K. and Gross, J. J. (2015), "Who turns green with envy? Conceptual and empirical perspectives on dispositional envy", European Journal of Personality, Vol. 29 No. 5, pp.530-547. https://doi.org/10.1002\%2Fper.2012

Rimé, B. (2009), "Emotion elicits the social sharing of emotion: theory and empirical review", Emotion Review, Vol. 1 No. $\quad 1, \quad$ pp.60-85. https://doi.org/10.1177\%2F1754073908097189

Salerno, A., Laran, J. and Janiszewski, C. (2019), "The bad can be good: when benign and malicious envy motivate goal pursuit”, Journal of Consumer Research, Vol. 46 No. 2, pp.388-405. https://doi.org/10.1093/jcr/ucy077

Salovey, P. and Rodin, J. (1988), "Coping with envy and jealousy”, Journal of Social and Clinical Psychology, Vol. 7 No. 1, pp.15-33. https://doi.org/10.1521/jscp.1988.7.1.15

Schachter, S. (1959), The Psychology of Affiliation: Experimental Studies of the Sources of Gregariousness, Stanford University Press, Stanford, CA.

Scholz, C., Baek, E. C., O’Donnell, M. B., Kim, H. S., Cappella, J. N. and Falk, E. B. (2017), "A neural model of valuation and information virality", Proceedings of the National 
Academy of Sciences, Vol. $114 \quad$ No. 11, pp.2881-2886. https://doi.org/10.1073/pnas.1615259114

Smith, R. H. (2004), "Envy and its transmutations", in Tiedens, L.Z. and Leach, C.W. (Ed.s), The Social Life of Emotions, Cambridge University Press, Cambridge, pp.43-63.

Stephen, A. T. (2016), "The role of digital and social media marketing in consumer behaviour", Current Opinion in Psychology, Vol. 10, pp.17-21. https://doi.org/10.1016/j.copsyc.2015.10.016

Stieglitz, S. and Dang-Xuan, L. (2013), "Emotions and information diffusion in social mediasentiment of microblogs and sharing behaviour", Journal of Management Information Systems, Vol. 29 No. 4, pp.217-248. https://doi.org/10.2753/MIS0742-1222290408

Strack, F., Schwarz, N. and Gschneidinger, E. (1985), "Happiness and reminiscing: the role of time perspective, affect, and mode of thinking", Journal of Personality and Social Psychology, Vol. 49 No. 6, pp.1460-1469. https://psycnet.apa.org/doi/10.1037/00223514.49.6.1460

Suárez Vázquez, A., Du, L. and Del Río Lanza, A. B. (2020), “Word of mouth: how upward social comparisons influence the sharing of consumption experiences", Journal of Consumer Behaviour, pp.1-12. https://doi.org/10.1002/cb.1902

Sun, T., Youn, S., Wu, G. and Kuntaraporn, M. (2006), “Online word-of-mouth (or mouse): An exploration of its antecedents and consequences", Journal of Computer-Mediated Communication, Vol. 11 No. 4, pp.1104-1127. https://doi.org/10.1111/j.10836101.2006.00310.x

Tandoc Jr, E. C., Ferrucci, P. and Duffy, M. (2015), "Facebook use, envy, and depression among college students: Is facebooking depressing?", Computers in Human Behavior, Vol. 43, pp.139-146. https://doi.org/10.1016/j.chb.2014.10.053 
Tesser, A. (2000), “On the confluence of self-esteem maintenance mechanisms", Personality and Social Psychology Review, Vol. 4 No. 4, pp.290-299. https://doi.org/10.1207\%2FS15327957PSPR0404_1

Tesser, A., Millar, M. and Moore, J. (1988), "Some affective consequences of social comparison and reflection processes: The pain and pleasure of being close", Journal of Personality and Social Psychology, Vol. 54 No. 1, pp.49-61. https://psycnet.apa.org/doi/10.1037/0022-3514.54.1.49

Tracy, J. L. and Robins, R. W. (2004), "Putting the self into self-conscious emotions: a theoretical model", Psychological Inquiry, Vol. 15 No. 2, pp.103-125. https://doi.org/10.1207/s15327965pli1502_01

Van de Ven, N., Zeelenberg, M., and Pieters, R. (2010), "Warding off the evil eye: when the fear of being envied increases prosocial behaviour", Psychological Science, Vol. 21 No. 11, pp.1671-1677. https://doi.org/10.1177\%2F0956797610385352

Van de Ven, N., Zeelenberg, M. and Pieters, R. (2011), "Why envy outperforms admiration”, Personality and Social Psychology Bulletin, Vol. 37 No. 6, pp.784-795. https://doi.org/10.1177\%2F0146167211400421

Wallace, L., James, T. L. and Warkentin, M. (2017), "How do you feel about your friends? Understanding situational envy in online social networks", Information and Management, Vol. 54 No. 5, pp.669-682. https://doi.org/10.1016/j.im.2016.12.010

Wenninger, H., Cheung, C. M. and Krasnova, H. (2019), “College-aged users behavioral strategies to reduce envy on social networking sites: A cross-cultural investigation”. Computers in Human Behavior, Vol. 97, pp.10-23. https://doi.org/10.1016/j.chb.2019.02.025

Wells, T. M. and Dennis, A. R. (2016), "To email or not to email: The impact of media on psychophysiological responses and emotional content in utilitarian and romantic 
communication", Computers in Human Behavior, Vol. 54, pp.1-9. https://doi.org/10.1016/j.chb.2015.07.036

Westbrook, R. A. (1987), "Product/consumption-based affective responses and postpurchase processes", Journal of Marketing Research, Vol. 24 No. 3, pp.258-270. https://doi.org/10.1177\%2F002224378702400302

Wobker, I. and Kenning, P. (2012), “Don't treat others better than me: Drivers and outcomes of customer envy", in Proceedings NeuroPsychoEconomics Conference (NPE) 2012, Erasmus University, Rotterdam, NL, Vol. 8, p.40.

Wobker, I. and Kenning, P. (2013), "Drivers and outcome of destructive envy behavior in an economic game setting”, Schmalenbach Business Review, Vol. 65 No. 2, pp.173-194. https://doi.org/10.1007/BF03396854

Wojnicki, A. C. and Godes, D (2008), "Word-of-mouth as self-enhancement", working paper [06-01], Harvard Business School, Harvard University, Boston: MA, 25 April.

Zajonc, R. B. (1980), "Feeling and thinking: preferences need no inferences", American Psychologist, Vol. 35 No. 2, pp.151-175. https://psycnet.apa.org/doi/10.1037/0003$066 X .35 .2 .151$

Zhang, M., Li, L., Ye, Y., Qin, K. and Zhong, J. (2020), "The effect of brand anthropomorphism, brand distinctiveness, and warmth on brand attitude: a mediated moderation model", Journal of Consumer Behaviour, Vol. 19 No. 5, pp.523-536. https://doi.org/10.1002/cb.1835 


\title{
Appendix: Scenarios of Study 1
}

\author{
Scenario 1 (Online-envy)
}

One imaginary morning, when checking your Facebook account, you find the following information:

One of your classmates achieved the job of his/her dreams and posted a picture in his/her new office.

One of your classmates is very happy because he/she passed a course (you failed the same course).

One of your classmates posted a picture of him/her enjoying a Saturday party (you could not join the party because you had to study).

One of your classmates announced that he/she made a wonderful public presentation. Everybody congratulated him/her for his/her success.

One of your classmates posts a picture with his/her new mobile phone. It is the same phone that you recently bought, but thanks to a promotion, your friend paid half the price that you paid.

\section{Scenario 2 (Online-no envy)}

One imaginary morning, when checking your Facebook account, you find the following information:

One of your classmates posted pictures of his/her new stamp collection.

One of your classmates recommends a course book.

One of your classmates posts the weather forecast for the following week.

One of your classmates shares a news item.

One of your classmates posts a picture with his/her new mobile phone. It is the same phone that you recently bought. 
Scenario 3 (Offline-envy)

One imaginary morning, you run into one of your classmates who tells you that he/she bought the same mobile phone that you have, but thanks to a promotion, your classmate paid half the price that you paid.

Scenario 4 (Offline-no envy)

One imaginary morning, you run into one of your classmates who tells you that he/she bought a new mobile phone. It is the same phone that you recently bought. 